DOI: https://doi.org/10.47405/mjssh.v5i1.380

\begin{tabular}{|c|c|}
\hline 4 & Malaysian Journal of Social Sciences and Humanities (MJSSH) \\
\hline $\begin{array}{l}\text { Malaysian Journal of } \\
\text { Social sciences and }\end{array}$ & Volume 5, Issue 1, January 2020 \\
\hline (MJ-SSH) & e-ISSN : 2504-8562 \\
\hline & $\begin{array}{l}\text { Journal home page: } \\
\text { www.msocialsciences.com }\end{array}$ \\
\hline
\end{tabular}

\title{
Amalan Kemahiran Pembelajaran Terarah Kendiri dalam Mata Pelajaran Sejarah: Perspektif Murid Tingkatan Dua
}

\author{
M. Kaviza ${ }^{1}$ \\ 1Pusat Pengajian Pendidikan dan Bahasa Moden, Universiti Utara Malaysia (UUM) \\ Correspondence: M. Kaviza (kavizakaviza@yahoo.com)
}

\begin{abstract}
Abstrak
Kajian secara deskriptif ini bertujuan untuk mengenal pasti tahap amalan kemahiran pembelajaran terarah kendiri dalam mata pelajaran sejarah. Seramai 865 orang murid Tingkatan Dua terlibat sebagai sampel kajian ini. Instrumen kajian ini ialah soal selidik kemahiran pembelajaran terarah kendiri yang diadaptasi yang telah disahkan oleh pakar penilai dan mempunyai nilai kebolehpercayaan yang baik. Data kajian ini dianalisis secara deskriptif iaitu min dan sisihan piawai dengan menggunakan perisian IBM SPSS versi 24. Dapatan kajian ini menunjukkan bahawa amalan kemahiran pembelajaran terarah kendiri berada pada tahap sederhana secara keseluruhannya. Dari segi konstruknya pula, ketiga-tiga konstruk dalam amalan kemahiran pembelajaran terarah kendiri iaitu pengurusan kendiri, keazaman untuk belajar dan kawalan kendiri juga berada pada tahap sederhana. Kajian ini menjadi sumber maklumat kepada guru-guru sejarah untuk memberi fokus kepada pemupukan amalan kemahiran pembelajaran terarah kendiri dalam proses pengajaran dan pembelajaran agar mereka lebih bertanggungjawab dan komited terhadap proses pembelajaran mereka secara berterusan.
\end{abstract}

Kata kunci: kemahiran pembelajaran terarah kendiri, mata pelajaran sejarah, kajian tinjauan

\section{Self-Directed Learning Skills Practice in History Subject: Perspective of Form Two Students}

\begin{abstract}
The descriptive study aims to identify the level of self-directed learning skills practice in history subject. A total of 865 students were involved in this study. The instrument of this study is a selfdirected learning skills questionnaire which has been validated by the content matters expert and has a good reliability value. The data of this study were analyzed descriptively using IBM SPSS software version 24. The findings of this study showed that the self-directed learning skills practice at the moderate level. Beside that, the construct in self-directed learning skills namely self-management, determination to learn and self-control also at moderate level. This study provided of meaningful information for history teachers about the incorporating self-directed learning skill practices in the teaching and learning process.
\end{abstract}

Keywords: self-directed learning skills, history subjects, survey study 


\section{Pengenalan}

Oleh kerana Kurikulum Standard Sekolah Menengah (KSSM) yang telah dilaksanakan secara berperingkat-peringkat mulai tahun 2017 adalah bertujuan untuk memenuhi keperluan dasar baharu di bawah Pelan Pembangunan Pendidikan Malaysia 2013-2025 dalam menjadikan kualiti kurikulum setanding dengan standard antarabangsa (Pusat Perkembangan Kurikulum, [PPK] 2016; Kementerian Pendidikan Malaysia [KPM], 2013). Justeru, penyepaduan elemen-elemen penting dalam kurikulum iaitu antara enam tunjang kerangka kurikulum (komunikasi, kerohanian, sikap dan nilai, kemanusiaan, ketrampilan diri, perkembangan fizikal dan estetika serta sains dan teknologi), pengingtegrasian pengetahuan, kemahiran dan nilai serta pengaplikasian kemahiran abad ke-21 dan kemahiran berfikir aras tinggi adalah disarankan bagi melahirkan insan murid yang seimbang dan harmonis dari segi intelek, rohani, emosi dan jasmani (PPK, 2016). Sehubungan dengan itu, adalah tidak dapat disangkal bahawa kurikulum sejarah juga tidak ketinggalan dalam mencapai matlamat kurikulum KSSM yang dihasratkan oleh pihak KPM iaitu meningkatkan pencapaian dan kemajuan negara dalam melahirkan murid untuk bersaing di peringkat global. Matlamat ini adalah bertepatan dengan matlamat kurikulum sejarah kerana murid yang arif dan peka terhadap ilmu sejarah mampu menyumbang kepada pembentukan masyarakat yang berdaya saing yang tinggi apabila mereka mempunyai amalan kemahiran pembelajaran terarah kendiri yang positif hasil daripada pengalamannya dengan persekitaran, di samping bertanggungjawab dan berkeyakinan terhadap proses pembelajaran dalam menghasilkan penghargaan kendiri dalam diri mereka sendiri (Nooriati Din, Shireen Haron \& Rahmah Mohd Rashid, 2016; Schuck, Jounell, Alford, Watson \& Belter, 2018). Sungguhpun begitu, sehingga hari tahap kemahiran pembelajaran terarah kendiri yang diamalkan oleh murid-murid dalam mata pelajaran sejarah masih belum diketahui lagi yang telah menimbulkan terdapat satu keperluan kepada pengkaji dalam kajian ini untuk menampung kelompangan yang timbul dalam pelaksanaan kurikulum sejarah. Maka, kajian ini adalah bertujuan untuk mengenal pasti tahap amalan kemahiran pembelajaran terarah kendiri dalam mata pelajaran sejarah dari perspektif murid tingkatan dua yang masih berada dalam proses penyesuaian pelaksanaan kurikulum KSSM.

\section{Objektif Kajian}

Objektif kajian ini ialah:

i. Mengenal pasti tahap amalan kemahiran pembelajaran terarah kendiri dari aspek pengurusan kendiri, keazaman untuk belajar dan kawalan kendiri dalam mata pelajaran sejarah.

\section{Soalan Kajian}

Soalan kajian ini ialah:
i. Apakah tahap amalan kemahiran pembelajaran terarah kendiri dalam mata pelajaran sejarah?
ii. Apakah tahap amalan pengurusan kendiri?
iii. Apakah tahap amalan keazaman untuk belajar?
iv. Apakah tahap amalan kawalan kendiri?

\section{Metod Kajian}

Kajian ini merupakan kajian berbentuk tinjauan dengan menggunakan soal selidik untuk mengenal pasti tahap amalan kemahiran pembelajaran terarah kendiri dalam mata pelajaran sejarah. Seramai 865 orang murid Tingkatan Dua yang dipilih melalui teknik persampelan rawak mudah telah dijadikan sampel dalam kajian ini. Instrumen kajian ini merupakan soal selidik kemahiran pembelajaran terarah kendiri yang diadaptasi yang terdiri daripada 40 item yang merangkumi tiga konstruk iaitu pengurusan kendiri, keazaman untuk belajar dan kawalan kendiri yang telah disahkan oleh dua orang pakar penilai dan mempunyai nilai kebolehpercayaan Cronbach Alfa iaitu 0.96 yang dianggap baik dan diterima 
untuk tujuan kajian ini (Nunnally, 1978). Data kajian ini dianalisis secara statistik deskriptif dengan menggunakan perisian IBM SPSS versi 24. Interpretasi tahap dan skor min amalan kemahiran pembelajaran terarah kendiri dalam kajian ini dilakukan berdasarkan tiga tahap yang diadaptasi daripada kajian Jamil Ahmad, (2002) seperti yang ditunjukkan pada Jadual 1.

Jadual 1: Interpretasi Skor Min dan tahap Kemahiran Pembelajaran Terarah Kendiri

\begin{tabular}{cc}
\hline Min & Tahap \\
\hline $1.00-2.33$ & Tinggi \\
$2.34-3.66$ & Sederhana \\
$3.67-5.00$ & Rendah \\
\hline
\end{tabular}

Sumber: Adaptasi daripada Jamil Ahmad, (2002)

\section{Dapatan Kajian}

\section{Apakah tahap amalan kemahiran pembelajaran terarah kendiri dalam mata pelajaran sejarah?}

Berdasarkan Jadual 2, amalan kemahiran pembelajaran terarah kendiri dalam mata pelajaran sejarah berada pada tahap sederhana $(M=3.26, S D=0.70)$. Oleh itu, tahap amalan kemahiran pembelajaran terarah kendiri secara keseluruhannya adalah sederhana dalam kajian ini.

Jadual 2: Tahap Amalan Kemahiran Pembelajaran Terarah Kendiri

\begin{tabular}{cccc}
\hline & Min & Sisihan Piawai & Tahap \\
\hline $\begin{array}{c}\text { Kemahiran pembelajaran } \\
\text { terarah kendiri }\end{array}$ & 3.26 & 0.70 & Sederhana \\
\hline
\end{tabular}

\section{Apakah tahap amalan pengurusan kendiri?}

Berdasarkan Jadual 3, amalan pengurusan kendiri berada pada tahap sederhana $(M=3.18, S D=0.80)$ secara keseluruhannya. Dari segi item pula, kesemua 13 item telah dilaporkan berada pada tahap sederhana iaitu item "Merancang menyelesaikan masalah" $(M=3.43, S D=1.17)$ dan item "Yakin meneruskan pembelajaran" $(M=3.43, S D=1.74)$ yang menunjukkan min yang tertinggi. Seterusnya, diikuti dengan item "Merancang pembelajaran" $(M=3.25, S D=1.13)$, item "Teratur" $(M=3.29$, $S D=1.07)$, item "Berkemahiran" $(M=3.19, S D=1.12)$, item "Berdisiplin" $(M=3.13, S D=1.24)$, item "Menetapkan masa belajar" $(M=3.11, S D=1.13)$, item "Yakin dengan kebolehan" $(M=3.11, S D=1.06)$, item "Mengatur pembelajaran" $(M=3.10, S D=1.10)$, item "Mengurus masa" $(M=3.09, S D=1.10)$, item "Sistematik" $(\mathrm{M}=3.09, S D=1.11)$, item "Mempunyai jadual waktu" $(M=3.07, S D=1.15)$ dan item Mengutamakan kerja" $(M=3.00, S D=1.14)$. Justeru, dapat disimpulkan bahawa amalan pengurusan kendiri dalam mata pelajaran sejarah berada pada tahap sederhana dalam kajian ini.

Jadual 3: Tahap Amalan Pengurusan Kendiri

\begin{tabular}{llccc}
\hline Bil & \multicolumn{1}{c}{ Item } & Min & $\begin{array}{c}\text { Sisihan } \\
\text { Piawai }\end{array}$ & Tahap \\
\hline 1 & Menguruskan masa & 3.09 & 1.10 & Sederhana \\
2 & Berdisplin & 3.13 & 1.24 & Sederhana \\
3 & Teratur & 3.29 & 1.07 & Sederhana \\
4 & Mempunyai jadual waktu & 3.07 & 1.15 & Sederhana \\
5 & Berkemahiran & 3.19 & 1.12 & Sederhana \\
6 & Sistematik & 3.09 & 1.11 & Sederhana \\
7 & Mengatur pembelajaran & 3.10 & 1.10 & Sederhana \\
8 & Menetapkan masa belajar & 3.11 & 1.13 & Sederhana \\
\hline
\end{tabular}



DOI: https://doi.org/10.47405/mjssh.v5i1.380

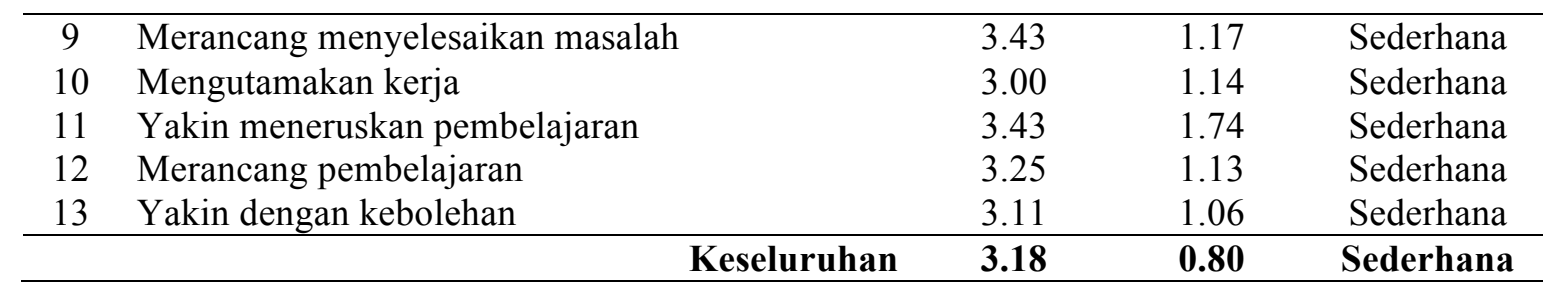

\section{Apakah tahap amalan keazaman untuk belajar?}

Berdasarkan Jadual 4, amalan keazaman untuk belajar berada pada tahap sederhana $(M=3.41$, $S D=0.79)$ secara keseluruhannya. Dari segi item pula, sebanyak tiga item telah dilaporkan berada pada tahap tinggi iaitu item "Ingin meneroka" $(M=3.67, S D=1.14)$, item "Mendalami sesuatu perkara" $(M=3.67, S D=0.99)$ dan item "Meminta bantuan luar" $(M=3.67, S D=1.09)$. Tambahan pula, sebanyak sembilan item yang lain telah dilaporkan berada pada tahap sederhana iaitu item "Gembira belajar" $(M=3.58, S D=1.13)$, item "Kritikal" $(M=3.48, S D=1.07)$, item "Suka cabaran" $(M=3.47, S D=1.78)$, item "Suka belajar" $(M=3.44, S D=1.12)$, item "Berfikiran terbuka" $(M=3.40, S D=1.10)$, item "Terus Belajar" $(M=3.27, S D=1.09)$, item "Menilai sesuatu perkara" $(M=3.17, S D=1.10)$, item "Menilai sesuatu perkara" $(M=3.17, S D=1.00)$ dan item "Membuat keputusan" $(M=2.98, S D=1.12)$. Justeru, dapat disimpulkan bahawa amalan keazaman untuk belajar dalam mata pelajaran sejarah berada pada tahap sederhana dalam kajian ini.

Jadual 4: Tahap Amalan Keazaman Untuk Belajar

\begin{tabular}{clccc}
\hline Bil & \multicolumn{1}{c}{ Item } & Min & $\begin{array}{c}\text { Sisihan } \\
\text { Piawai }\end{array}$ & Tahap \\
\hline 1 & Ingin meneroka & 3.67 & 1.14 & Tinggi \\
2 & Gembira belajar & 3.58 & 1.13 & Sederhana \\
3 & Terus belajar & 3.27 & 1.09 & Sederhana \\
4 & Suka cabaran & 3.47 & 1.78 & Sederhana \\
5 & Suka belajar & 3.44 & 1.12 & Sederhana \\
6 & Kritikal & 3.48 & 1.07 & Sederhana \\
7 & Membuat keputusan & 2.98 & 1.12 & Sederhana \\
8 & Menilai sesuatu perkara & 3.17 & 1.00 & Sederhana \\
9 & Berfikiran terbuka & 3.40 & 1.10 & Sederhana \\
10 & Belajar dari kesilapan & 3.17 & 1.10 & Sederhana \\
11 & Mendalami sesuatu perkara & 3.67 & 0.99 & Tinggi \\
12 & Meminta bantuan luar & 3.67 & 1.09 & Tinggi \\
\hline & & & & \\
\hline
\end{tabular}

\section{Apakah tahap amalan kawalan kendiri?}

Berdasarkan Jadual 5, amalan kawalan kendiri berada pada tahap sederhana $(M=3.21, S D=0.74)$ secara keseluruhannya. Dari segi item pula, kesemua item telah dilaporkan berada pada tahap sederhana iaitu item "Percaya kebolehan" $(M=3.44, S D=1.04)$ dan item "Menetapkan kriteria" $(M=3.44, S D=1.06)$ yang menunjukkan min yang tertinggi. Seterusnya, diikuti dengan item "Sedar akan kelemahan diri" $(M=3.43, S D=1.01)$, item "Bertanggungjawab" $(M=3.42, S D=1.08)$, item "Mengawal kehidupan" $(M=3.39, S D=1.00)$, item "Menilai pencapaian" $(M=3.33, S D=1.09)$, item "Mendapatkan maklumat" $(M=3.23, S D=1.09)$, item "Berfikir secara logik" $(M=3.13, S D=1.06)$, item "Menetapkan matlamat diri" $(M=3.12, S D=1.27)$, item "Menentukan matlamat pembelajaran" $(M=3.12, S D=1.12)$, item "Berkeperibadian tinggi" $(M=3.10, S D=1.08)$, item "Harapan tinggi" $(M=3.07, S D=1.09)$, item "Memberi perhatian" $(M=3.06, S D=1.14)$, item "Bertanggungjawab dalam keputusan" $(M=2.96$, $S D=1.06)$ dan item "Membuat keputusan" $(M=2.89, S D=1.03)$. Justeru, dapat disimpulkan bahawa amalan kawalan kendiri dalam mata pelajaran sejarah berada pada tahap sederhana dalam kajian ini. 
DOI: https://doi.org/10.47405/mjssh.v5i1.380

Jadual 5: Tahap Amalan Kawalan Kendiri

\begin{tabular}{clccc}
\hline Bil & \multicolumn{1}{c}{ Item } & Min & $\begin{array}{c}\text { Sisihan } \\
\text { Piawai }\end{array}$ & Tahap \\
\hline 1 & Menetapkan matlamat diri & 3.12 & 1.27 & Sederhana \\
2 & Membuat keputusan & 2.89 & 1.03 & Sederhana \\
3 & Bertanggungjawab dalam keputusan & 2.96 & 1.06 & Sederhana \\
4 & Mengawal kehidupan & 3.39 & 1.00 & Sederhana \\
5 & Berkeperibadian tinggi & 3.10 & 1.08 & Sederhana \\
6 & Menentukan matlamat pembelajaran & 3.12 & 1.12 & Sederhana \\
7 & Menilai pencapaian & 3.33 & 1.09 & Sederhana \\
8 & Berfikir secara logik & 3.13 & 1.06 & Sederhana \\
9 & Bertanggungjawab & 3.42 & 1.08 & Sederhana \\
10 & Harapan tinggi & 3.07 & 1.09 & Sederhana \\
11 & Memberi perhatian & 3.06 & 1.14 & Sederhana \\
12 & Sedar kelemahan diri & 3.43 & 1.01 & Sederhana \\
13 & Mendapatkan maklumat & 3.23 & 1.09 & Sederhana \\
14 & Percaya kebolehan & 3.44 & 1.04 & Sederhana \\
15 & Menetapkan kriteria & 3.44 & 1.06 & Sederhana \\
\hline & & $\mathbf{3 . 2 1}$ & $\mathbf{0 . 7 4}$ & Sederhana \\
\hline
\end{tabular}

\section{Perbincangan Kajian}

Amalan kemahiran pembelajaran terarah kendiri yang dilaporkan berada pada tahap sederhana dalam mata pelajaran sejarah dalam kajian ini adalah sealiran dengan dapatan kajian Shankar dan Nandy (2016), kajian Tekkol dan Demirol (2018) dan kajian Kaviza (2019) yang telah melaporkan bahawa persepsi terhadap kemahiran pembelajaran terarah kendiri bagi murid yang mengikuti pembelajaran berasaskan masalah, pembelajaran sepanjang hayat dan pembelajaran berasaskan analisis sumber teks sejarah berada pada tahap sederhana. Sungguhpun begitu, dapatan kajian ini juga didapati bertentangan dengan dapatan kajian Lim, Abu Bakar Razali dan Arshad Abdul Samad (2018) yang telah melaporkan bahawa tahap amalan kemahiran terarah kendiri dalam mempelajari bahasa Inggeris adalah tinggi dan kajian Dynan, Cate dan Rhee (2008) yang telah melaporkan bahawa tahap kemahiran pembelajaran terarah kendiri adalah baik bagi murid yang mengikuti reka bentuk pembelajaran secara berstruktur. Tambahan pula, konstruk-konstruk dalam amalan kemahiran pembelajaran terarah kendiri dalam kajian ini yang berada pada tahap sederhana adalah bertentangan dengan dapatan kajian Ors (2018) yang telah melaporkan bahawa dua konstruk dalam kemahiran pembelajaran terarah kendiri iaitu desire for learning dan self-management mempunyai skor min yang tinggi walaupun konstruk self-control telah melaporkan skor min yang rendah dalam kalangan murid sarjana muda dalam bidang nursing dan midwifery.

Oleh kerana tahap kemahiran pembelajaran terarah kendiri dalam mata pelajaran sejarah adalah sederhan dalam kajian ini, maka terdapat keperluan kepada guru-guru untuk melaksanakan proses pembelajaran sejarah yang dapat melahirkan murid yang mempunyai kemahiran-kemahiran abad ke-21 seperti berdaya tahan, mahir berkomunikasi, pemikir, kerja berpasukan, bersifat ingin tahu, berprinsip, bermaklumat, penyayang dan prihatin dan patriotic dengan memberi penekanan kepada kemahiran berfikir, kebolehcapaian kognitif dan kemahiran hidup yang berteraskan kepada amalan nilai murni secara berterusan (Schweder 2019; PPK, 2016; Janet, Jolly dan Christina, 2020; Maimunah Nasir \& Hashimah Mohd Yunus, 2017; Adenan Ayob \& Nazri Abu Bakar, 2018; Mistirine Radin, 2018). Sehubungan dengan itu murid-murid yang mempelajari mata pelajaran sejarah perlulah sentiasa bersedia dengan pelbagai kemahiran yang bersifat global dan berperanan sebagai pembelajar sepanjang hayat yang sentiasa mempunyai dorongan dalaman untuk membentuk konsep kendiri melalui penilaian, persepsi dan kepercayaan terhadap dirinya (Candy, 1991; Knowles, 1975; Suppiah, Nachiapan, Ramlah Jantan \& Abdul Aziz Abdul Shukor, 2009). 


\section{KESIMPULAN}

Kesimpulannya, keupayaan membentuk kemahiran pembelajaran terarah kendiri adalah penting dalam konteks pendidikan sejarah yang menjadi pemangkin kepada kejayaan seseorang murid dan melahirkan modal insan seperti yang dihasratkan dalam Falsafah Pendidikan Kebangsaan. Justeru, pendekatan dalam pengajaran dan pembelajaran yang dilaksanakan dalam mata pelajaran sejarah perlulah mengambil kira aspek penyepaduan pengetahuan, kemahiran dan nilai yang dapat memperkukuh identiti diri dan semangat setia negara seiring dengan pembentukan ciri-ciri murid abad ke-21 (PPK, 2016).

\section{Rujukan}

Adenan Ayob \& Nazri Abu Bakar. (2018). Interpretasi Hubungan Pembelajaran Terarah kendiridengan Kebolehcapaian kognitif Berasaskan Fahaman Konstruktivis. International Journal of Education, Psychology and Counseling, 3(10), 75-87.

Candy, P.C. (1991). Self-direction for lifelong learning: A comprehensive guide to theory and practice. San Fransico; Jose Bass

Dynan, L., Caye, T \& Rhee, K. (2008). The impact of learning structure on student readiness for selfdirected learning. Journal of Education for Business, 84(2), 96-100.

Jamil Ahmad. (2002). Pemupukan Budaya Penyelidikan di Kalangan Guru di Sekolah: Satu Penilaian. Tesis Ijazah Kedoktoran, Fakulti Pendidikan: Universiti Kebangsaan Malaysia.

Janet, J.J.T dan Christina, A. (2020). Peranan aktif pelajar pengajian perniagaan dalam membentuk kemahiran pembelajaran terarah kendiri melalui pembelajaran berasaskan masalah. International Journal of Education and Pedagogy, 2(1), 23-42.

Kaviza, M. (2019). Penerokaan kemahiran terarah kendiri melalui analisis sumber teks sejarah. EDUCATUM: Journal of Social Sciences (EJoSS), 5(1), 45-53.

Kementerian Pendidikan Malaysia. (2013). Pelan Pembanguan Pendidikan Malaysia 2013-2025. Putrajaya: Kementerian Pendidikan Malaysia.

Knowles, M. (1975). Self-Directed Learning: A Guide for learners and teachers. New York: Associated Press.

Lim, Y.X., Abu Bakar Razali \& Arshad Abd, Samad. (2018). Self-directed learning readiness (SDLR) among foundations students from high and low proficiency levels to learn English language. Malaysian Journal of Learning and Instruction, 1592), 55-81.

Maimunah Nasir \& Hashimah Mohd Yunus. (2017). Peranan guru tingkatan enam dalam membentuk pelajar terarah kendiri dan meningkatkan kemahiran abad ke-21. Jurnal Kurikulum dan Pengajaran Asia Pasifik, 5(1), 1-6.

Mistirine Radin, A.M.Z.Y. (2018). The implementation of the $21^{\text {st }}$ Century Education in Malaysia: A preliminary review. Sains Humanika, 10(3-2), 1-6.

Norriati Din, Shireen Haron \& Rahmah Mohd Rashid. (2016). Can self-directed learning environment improve quality of life? Proceedia Social and Behavioral Science, 222, 219-227.

Nunnally, J.C. (1978). Psychometrie Theory $\left(2^{\text {nd }}\right.$ Ed). New York: McGraw Hill.

Ors, M. (2018). The self-directed learning readiness level of the undergraduate students of midlife and nurse in terms of sustainability in nursing and midwifery education. Sustainability, 10(3574), 114.

Pusat Perkembangan Kurikulum. (2016). Dokumen standard kurikulum dan pentaksiran mata pelajaran sejarah tingkatan dua. Putrajaya: Kementerian Pendidikan Malaysia.

Schuck, D.H., Jounell, W., Alford, A., Watson, J. \& Belter, M. (2018). Self-regulated learning in the social studies classroom. In. M.K DiBeneddeto (eds.), Connecting self-regulated learning performances with instruction across high school content across, 89-124.

Schweder, S. (2019). Mastery goals, positive emotions and learning behavior in self-directed vs teacher-directed learning. European Journal of Psychology Education, 1-19.

Shankar, D. R \& Nandy, A. (2016). Self-directed learning during problem based learning sessions. MedEdPublish, 5(3), 1-10.

Suppiah Nachiappan, Ramlah Jantan \& Abdul Aziz Abdul Shukor. (2008). Psikologi Pendidikan. Shah Alam: Oxford Fajar Sdn Bhd. 
Malaysian Journal of Social Sciences and Humanities (MJSSH), Volume 5, Issue 1, (page 109 - 115), 2020

DOI: https://doi.org/10.47405/mjssh.v5i1.380

Tekkol, I.A \& Demiral, M. (2018). An investigation of self-directed learning skills of undergraduate students. Frontier in Psychology, 9, 1-14. 